\title{
Synthesis of high saturation magnetization FeCo nanoparticles by polyol reduction
}

\section{method}

$$
\text { F.J. Yang a,b J. Yao }{ }^{\text {a,b }} \text {, J.J. Min }{ }^{\text {a,b }} \text { J.H. Li }{ }^{\text {a,b }} \text {, X.Q. Chen }{ }^{\text {a,b,** }}
$$

${ }^{a}$ Hubei Collaborative Innovation Center for Advanced Organic Chemical Hubei University, Wuhan 430062,

$$
\text { P.R. China }
$$

${ }^{b}$ Faculty of Physics and Electronic Science, Key Laboratory of Ferro- and Piezo-electric Materials and Devices, Hubei University, Wuhan 430062, P.R. China

\begin{abstract}
FeCo nanoparticles with different compositions were prepared by a polyol reduction method and annealed in gas mixtures. All FeCo nanoparticles show large saturation magnetization (over $220 \mathrm{emu} / \mathrm{g}$ ). The largest saturation magnetization of $273 \mathrm{emu} / \mathrm{g}$ was observed in the $\mathrm{Fe}_{55} \mathrm{Co}_{45}$ sample. As for $\mathrm{Fe}_{48} \mathrm{Co}_{52}$, the impurity phase of $\mathrm{CoFe}_{2} \mathrm{O}_{4}$ existed when nanoparticles were annealed at low temperature $\left(200\right.$ to $\left.400{ }^{\circ} \mathrm{C}\right)$. While annealed at above $450{ }^{\circ} \mathrm{C}$, pure $\mathrm{Fe}_{48} \mathrm{Co}_{52}$ nanoparticles with large saturation magnetization of $230 \mathrm{emu} / \mathrm{g}$ were obtained. These FeCo nanoparticles with large saturation magnetization have great potential in some industry fields.
\end{abstract}

PACS: 75.50.Tt, 75.60.Ej, 75.50.Ss

Keywords: Polyol reduction method, FeCo nanoparticles, Microstructure, Magnetic properties

\footnotetext{
* Corresponding author: Tel.: +86 27 88663390; E-mail address: chxq@hubu.edu.cn
} 


\section{Introduction}

Magnetic nanoparticles with high saturation magnetization $\left(M_{s}\right)$ have attracted wide attention due to their great potential in data storage, magnetic separation, drug delivery and imaging applications [1,2]. For example, magnetic nanoparticles used in hyperthermia and targeted drug delivery require high $M_{s}$ for their easy manipulation through magnetic field assistance. Furthermore, magnetic nanoparticles with high $M_{s}$ have been developed for magnetic resonance imaging contrast enhancement [3]. Similarly, for biosensor application, high magnetic moments are required for efficient shift of the functionalized labels to the specific sensor sites [4,5].

FeCo based nanoparticles have got much attention due to their high $M_{s}$, large permeability, low coercivity $\left(H_{c}\right)$, and high Curie temperature [6,7]. FeCo based nanoparticles have been prepared through several methods, such as sol-gel method [8], electrochemical deposition [9], magnetron sputtering [10], thermal decomposition [11], chemical vapor deposition [12]. However, there are some limitations including complex synthesis process, long synthesis duration, use of environmentally harmful chemicals, high production cost. Compared with these methods, polyol process is a simple, environmental friendly, easy control of experimental parameters and low cost method [5,13]. Polyols act as reducing agent also overcomes the problem of oxidation of metal particles in solution.

In this work, FeCo nanoparticles with different composition were prepared by a polyol reduction method and followed by annealing in reductive atmosphere. The obtained FeCo nanoparticles show satisfactory microstructure and high $M_{s}$.

\section{Materials and methods}

In a typical synthesis procedure, FeCo particles with different composition were prepared 
by using $\mathrm{FeCl}_{2} \cdot 4 \mathrm{H}_{2} \mathrm{O}, \mathrm{Co}(\mathrm{Ac})_{2} \cdot 4 \mathrm{H}_{2} \mathrm{O}, \mathrm{NaOH}$ and ethylene glycol. The concentration of metal salts was fixed at $0.05 \mathrm{~mol} / \mathrm{L}$ and the $\mathrm{Fe} / \mathrm{Co}$ molar ratio was varied according to the anticipated composition. Then a certain amount of $\mathrm{NaOH}$ was added to provide an alkaline environment. The mixed solution was subsequently ultrasonicated for 5 minutes and heated to $130{ }^{\circ} \mathrm{C}$ for $3 \mathrm{~h}$ in an erlenmeyer flask. After that, the black precipitation at the flask bottom was collected with a magnet and ultrasonic washed several times using ethanol and water. Finally, the cleaned black particles were annealed in $90 \% \mathrm{Ar}$ and $10 \% \mathrm{H}_{2}$ mixed gas.

The composition of the particles was analyzed by x-ray fluorescence (XRF-1800) instrument and energy dispersive x-ray spectroscopy (EDX) fitted to a scanning electron microscopy (SEM). The morphology of the particles was analyzed by using SEM (JSM 7100). The crystal structure was determined by x-ray diffraction (XRD, Bruker D8) and the magnetic properties were measured at room temperature using a vibrating sample magnetometer (VSM, LakeShore model 7400).

\section{Results and discussion}

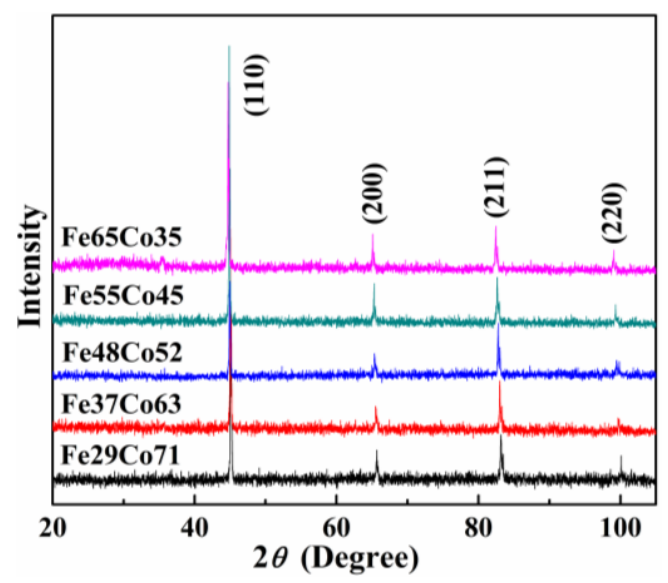

Fig. 1. The XRD patterns of FeCo nanoparticles with different $\mathrm{Fe}$ 、 Co composition annealed at $850^{\circ} \mathrm{C}$ for $5 \mathrm{~h}$.

Figure 1 shows the XRD patterns of FeCo nanoparticles with different composition annealed at $850{ }^{\circ} \mathrm{C}$ for $5 \mathrm{~h}$. It can be seen that no impurity phases are detected, and all diffraction peaks can be indexed corresponding to the standard JCPDS data for FeCo (No: 
49-1567), indicating the formation of single phase FeCo. Furthermore, all the diffraction peaks shifted slightly towards lower angle with increasing Fe composition. This is caused by the substitution of Fe atoms with larger atomic radius for Co atoms with smaller atomic radius, which would induce the expansion of the FeCo unit cell.

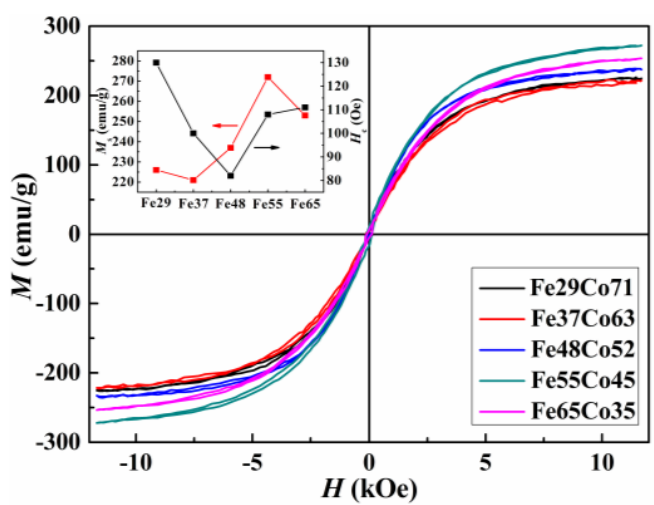

Fig. 2. The room temperature hysteresis loops of FeCo nanoparticles annealed at $850{ }^{\circ} \mathrm{C}$ for $5 \mathrm{~h}$ with different $\mathrm{Fe} 、 \mathrm{Co}$ composition. Inset: the composition dependence of $M_{s}$ and $H_{c}$ in FeCo nanoparticles.

Figure 2 shows the room temperature hysteresis loops of FeCo nanoparticles with different compositions annealed at $850{ }^{\circ} \mathrm{C}$ for $5 \mathrm{~h}$. The inset shows the dependence of $M_{s}$ and $H_{c}$ on the composition of FeCo nanoparticles. The $M_{s}$ of all FeCo nanoparticles is over $220 \mathrm{emu} / \mathrm{g}$. In $\mathrm{Fe}_{55} \mathrm{Co}_{45}$ sample, we have obtained the $M_{s}$ of $273 \mathrm{emu} / \mathrm{g}$. Although the value is smaller than the theoretical prediction [14], it is larger than the previously reported values until now [13]. Among all the samples, the samples with high cobalt content (over 50\%) show smaller $M_{s}$ which might be attributed to the higher magnetic moment of Fe compared with Co. Besides, the lowest $H_{c}$ of 82 Oe was observed in the $\mathrm{Fe}_{48} \mathrm{Co}_{52}$ sample, which is due to much more pure FeCo samples and less impurities and defects. The existence of impurities and defects will act as pinning sites to enhance the coercivity and decrease the magnetic anisotropy energy. The magneto-crystalline anisotropy was reported to be compositionally dependent and would reach its maximum in a little more Co-rich FeCo samples [14, 15].

The XRD patterns of $\mathrm{Fe}_{48} \mathrm{Co}_{52}$ nanoparticles annealed at different temperatures for $5 \mathrm{~h}$ are 
shown in Fig. 3. When annealed at $200{ }^{\circ} \mathrm{C}$ and $350{ }^{\circ} \mathrm{C}$, except obvious reflections belonging to $\mathrm{FeCo}$, the peaks at $30.1^{\circ}, 35.4^{\circ}, 57^{\circ}$ and $62.6^{\circ}$ corresponding to (220), (311), (511) and (440) reflections of $\mathrm{CoFe}_{2} \mathrm{O}_{4}$ are present. The appearance of $\mathrm{CoFe}_{2} \mathrm{O}_{4}$ might be attributed to the partially oxidation of $\mathrm{Fe}_{48} \mathrm{Co}_{52}$ nanoparticles. With increasing annealing temperature $\left(T_{a}\right)$ to $400{ }^{\circ} \mathrm{C}$, the intensity of the (311), (440) peaks decrease and the (220), (511) peaks disappear. With further increasing $T_{a}$ to $450{ }^{\circ} \mathrm{C}$, all of the $\mathrm{CoFe}_{2} \mathrm{O}_{4}$ reflections vanished and only $\mathrm{FeCo}$ diffraction peaks were observed.

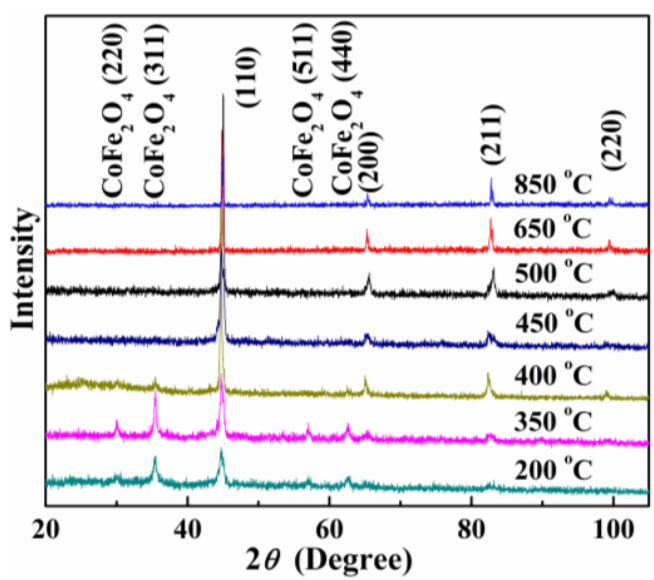

Fig. 3. The XRD patterns of $\mathrm{Fe}_{48} \mathrm{Co}_{52}$ nanoparticles annealed at different temperatures from 200 to $850{ }^{\circ} \mathrm{C}$ for $5 \mathrm{~h}$.

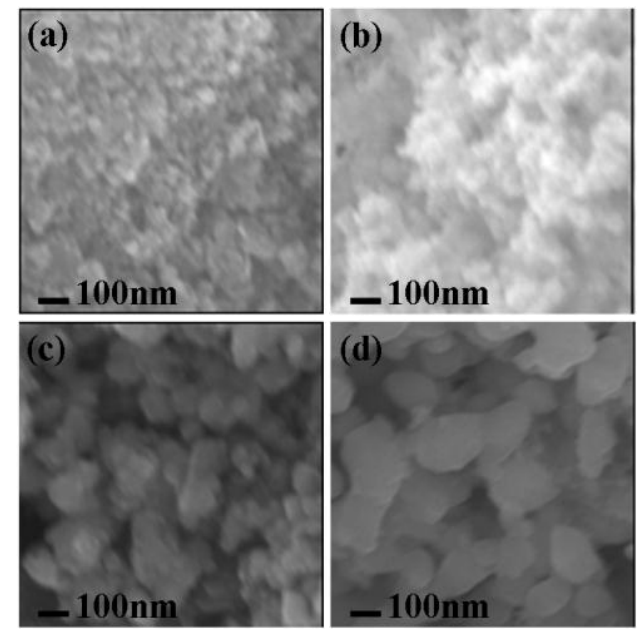

Fig. 4. The SEM images of $\mathrm{Fe}_{48} \mathrm{Co} 2$ nanoparticles annealed at (a) $300{ }^{\circ} \mathrm{C}$ (b) $400{ }^{\circ} \mathrm{C}$ (c) $450{ }^{\circ} \mathrm{C}$ (d) $500{ }^{\circ} \mathrm{C}$.

The SEM images of $\mathrm{Fe}_{48} \mathrm{Co}_{52}$ nanoparticles with different $T_{a}$ ranging from $300{ }^{\circ} \mathrm{C}$ to 500 ${ }^{\circ} \mathrm{C}$ are shown in Fig. 4. When annealed at low temperature $\left(300{ }^{\circ} \mathrm{C}\right.$ and $\left.400{ }^{\circ} \mathrm{C}\right)$, small and uniform particles were observed. The average particle size was estimated to be about $40 \mathrm{~nm}$. 
When increasing $T_{a}$ to $450{ }^{\circ} \mathrm{C}$, the average particle size increased sharply from about $40 \mathrm{~nm}$ to about $100 \mathrm{~nm}$. The formation of large particles might be due to the aggregation of small particles, which is induced by the strong magnetic interaction between FeCo grains [16]. When further increasing $T_{a}$ to $500{ }^{\circ} \mathrm{C}$, much larger particles were observed because of the growth of the grains and more aggregation of small particles.

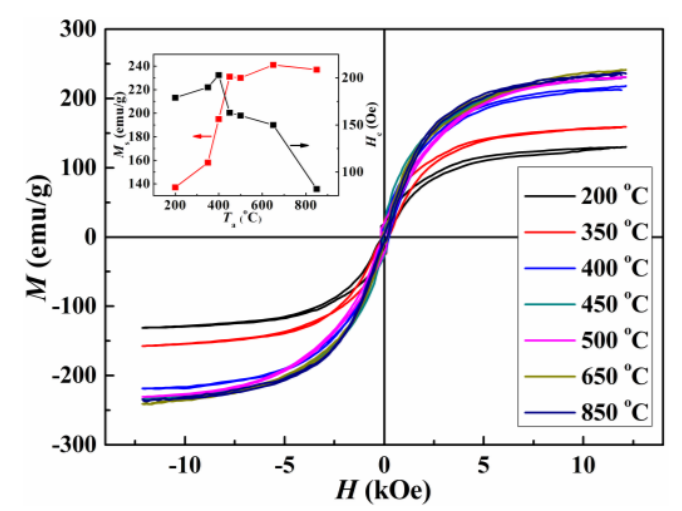

Fig. 5. The room temperature hysteresis loops of $\mathrm{Fe}_{48} \mathrm{Co} 52$ nanoparticles annealed at different temperatures for $5 \mathrm{~h}$. Inset: the $T_{a}$ dependence of $M_{s}$ and $H_{c}$ in $\mathrm{Fe}_{48} \mathrm{Co} 25$ nanoparticles.

Figure 5 shows the room temperature hysteresis loops of $\mathrm{Fe}_{48} \mathrm{Co}_{52}$ nanoparticles annealed at different temperatures for $5 \mathrm{~h}$. The inset shows the dependence of $M_{s}$ and $H_{c}$ on $T_{a}$ in $\mathrm{Fe}_{48} \mathrm{Co}_{52}$ nanoparticles. It can be seen that the $M_{s}$ of $\mathrm{Fe}_{48} \mathrm{Co}_{52}$ nanoparticles increases rapidly with increasing $T_{a}$ from $200{ }^{\circ} \mathrm{C}$ to $400{ }^{\circ} \mathrm{C}$. The sharp increase of $M_{s}$ is due to the reduction of $\mathrm{CoFe}_{2} \mathrm{O}_{4}$ and more complete phase transformation. When $\mathrm{Fe}_{48} \mathrm{Co}_{52}$ nanoparticles were annealed at $450{ }^{\circ} \mathrm{C}$, large $M_{s}$ of $230 \mathrm{emu} / \mathrm{g}$ was obtained. With further increasing $T_{a}$, the $M_{s}$ has little change which might be attributed to the finish of phase transformation. Furthermore, we can find that the $H_{c}$ increases firstly and then decreases with increasing $T_{a}$. The maximum $H_{c} \sim 203$ Oe was obtained when $T_{a}$ is $400{ }^{\circ} \mathrm{C}$. When annealed at below $400{ }^{\circ} \mathrm{C}, \mathrm{Fe}_{48} \mathrm{Co} \cos _{2}$ nanoparticles might be in a single-domain state because of small particle size indicated in Fig. 4(a) and (b), and the magnetization reversal occurs by rotation of all the magnetic moment which requires the anisotropy energy to be dominated. With increasing $T_{a}$ to $450{ }^{\circ} \mathrm{C}$, the 
multidomain state is favored since the size of particles increase, as shown in Fig. 4(c) and (d), and the magnetization is changed to the movement of domain walls. Since the anisotropy energy is much higher than domain wall energy, the $H_{c}$ increases to the maximum value when $T_{a}$ is $400{ }^{\circ} \mathrm{C}$ and then decreases because the formation of multidomain nanoparticles in $\mathrm{FeCo}$ samples [17].

\section{Conclusions}

In summary, FeCo nanoparticles with different compositions were prepared by a polyol reduction method. When annealed at $850{ }^{\circ} \mathrm{C}$ for $5 \mathrm{~h}$, all $\mathrm{FeCo}$ nanoparticles with $\mathrm{Fe}$ atomic concentration ranging from $29 \%$ to $65 \%$ show large $M_{s}$ (over $220 \mathrm{emu} / \mathrm{g}$ ). The largest $M_{s}$ of $273 \mathrm{emu} / \mathrm{g}$ and the lowest $H_{c}$ of 82 Oe were obtained in $\mathrm{Fe}_{55} \mathrm{Co}_{45}$ and $\mathrm{Fe}_{48} \mathrm{Co}_{52}$ nanoparticles respectively.

\section{Acknowledgements}

The authors are grateful for financial support from the National Science Foundation of China (Grant No.11274101 and 51002047). 


\section{Reference}

[1] N.A. Frey, S. Peng, K. Cheng, S.H. Sun, Chem. Soc. Rev. 38 (2009) 2532.

[2] T.L. Doane, C. Burda, Chem. Soc. Rev. 41 (2012) 2885.

[3] W.S. Seo, J.H. Lee, X.M. Sun, Y. Suzuki, D. Mann, Z. Liu, M. Terashima, P.C. Yang, M.V. McConnell, D.G. Nishimura, H.J. Dai, Nature Mater. 5 (2006) 971.

[4] E.P. Furlani, K.C. Ng, Phy. Rev. E. 73 (2006) 061919.

[5] R.J. Joseyphus, K. Shinoda, D. Kodama, B. Jeyadevan, Mater. Chem. Phys. 123 (2010) 487.

[6] D. Kodama, K. Shinoda, K. Sato, Y. Konno, R.J. Joseyphus, K. Motomiya, H. Takahashi, T. Matsumoto, Y. Sato, K. Tohji, B. Jeyadevan, Adv. Mater. 18 (2006) 3154.

[7] C. Desvaux, C. Amiens, P. Fejes, P. Renaud, M. Respaud, P. Lecante, E. Snoeck, B. Chaudret, Nature Mater. 4 (2005) 750.

[8] G. Ennas, A. Falqui, S. Marras, C. Sangregorio, G. Marongiu, Chem. Mater. 16 (2004) 5659.

[9] C.W. Qiang, J.C. Xu, S.T. Xiao, Y.J. Jiao, Z.Q. Zhang, Y. Liu, L.L. Tian, Z.G. Zhou, Appl. Surf. Sci. 257 (2010) 1371.

[10] S. Li, Z. Huang, J.G. Duh, M. Yamaguchi, Appl. Phys. Lett. 92 (2008) 092501.

[11] V. Tzitzios, G. Basina, D. Niarchos, W.F. Li, G. Hadjipanayis, J. Appl. Phys. 109 (2011) 07A313.

[12] D. Hisada, Y. Fujiwara, H. Sato, M. Jimbo, T. Kobayashi, K. Hata, J. Magn. Magn. Mater. $323(2011) 3184$

[13] M. Abbas, M.N. Islam, B.P. Rao, T. Ogawa, M. Takahashi, C.G. Kim, Mater. Lett. 91 (2013) 326 .

[14] G. Moulas, A. Lehnert, S. Rusponi, J. Zabloudil, C. Etz, S. Ouazi, M. Etzkorn, P. Bencok, P. Gambardella, P. Weinberger, H. Brune, Phys. Rev. B 78 (2008) 214424.

[15] G. Andersson, T. Burkert, P. Warnicke, M. Björck, B. Sanyal, C. Chacon, C. Zlotea, L. 
Nordström, P. Nordblad, O. Eriksson, Phys. Rev. Lett. 96 (2006) 037205.

[16] J.M. MacLaren, T.C. Schulthess, W.H. Butler, R. Sutton, M. McHenry, J. Appl. Phys. 85 (1999) 4833.

[17] M. Hesani, A. Yazdani, B. Abedi Ravan, M. Ghazanfari, Solid State Commun. 150 (2010) 594. 


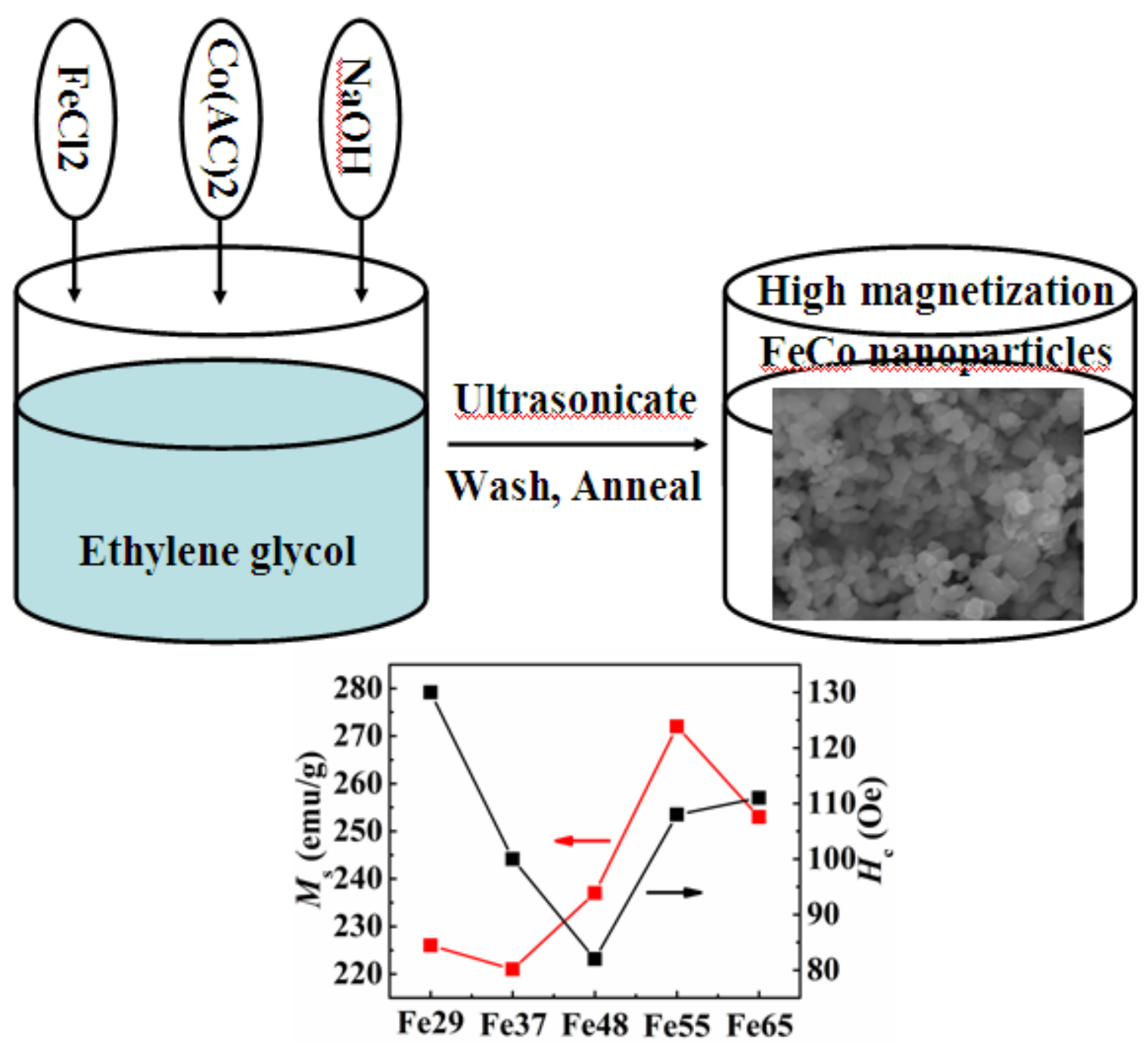

